\title{
Prognosis of Down's syndrome with acute leukaemia
}

\author{
G A Levitt, C A Stiller, J M Chessells
}

\begin{abstract}
The outcome in children with acute leukaemia with $(n=90)$ and without Down's syndrome $(n=4377)$ was compared. Sixty three $(70 \%)$ of those with Down's syndrome had acute lymphoblastic leukaemia and in comparison with $3664(84 \%)$ controls had similar prognostic features except for a significant excess of the 'common' immunological subtype of acute lymphoblastic leukaemia. The outcome of the children with Down's syndrome was significantly worse with a five year overall actuarial survival of $28 \%$ compared with $59 \%$ in the control group. It appeared that both suboptimal chemotherapy and a high rate of infective problems contributed to the poor survival. Twenty six children with Down's syndrome had acute myeloblastic leukaemia and were significantly younger and had a higher percentage of the megakaryocytic and erythroid subtypes of acute myeloblastic leukaemia than the 713 controls. The outcome was similar in the two groups.

It is concluded that the patients with Down's syndrome who develop acute leukaemia should receive standard protocols without modification, but aggressive supportive care is necessary to improve outcome.
\end{abstract}

The first reported case of the occurrence of Down's syndrome and acute leukaemia was made in an infant in $1930 .{ }^{1}$ It was over 30 years later before Krivit and Good, in a nationwide American survey, found more than a casual association between these two conditions. ${ }^{2}$ Further studies showed that children with Down's syndrome had a 15-30 fold increased incidence of leukaemia. ${ }^{34}$ The life expectancy of children with Down's syndrome has increased with more effective treatment of respiratory infections and congenital heart disease. In a recent cohort from Canada $81.9 \%$ who had no major congenital heart disease were still alive at 20 years, though substantially fewer of those with congenital heart disease survived. ${ }^{5}$ There has thus been an increase in the proportion of children with Down's syndrome surviving to develop leukaemia. This factor coupled with the concept that these children should be treated as normal children and be given every opportunity of cure for any life threatening disease has increased the numbers being referred to specialist paediatric oncology and haematology centres.

With this in mind the aim of the study was to investigate the present outcome of children with Down's syndrome and acute leukaemia.

\section{Patients and methods}

The National Registry of Childhood Tumours at the Childhood Cancer Research Group (CCRG), with ascertainment based on the national cancer registration scheme, includes the great majority of children aged under 15 years with malignant disease in Great Britain. ${ }^{6}$ The United Kingdom Children's Cancer Study Group (UKCCSG) has a register of patients treated by its members throughout the United Kingdom and the Irish Republic and a copy of this register is also kept at the CCRG. The files of both registers were searched for children with Down's syndrome and acute leukaemia diagnosed between 1971 and 1986, and those patients treated by members of the UKCCSG at 17 centres were identified. Permission was requested to use these patients in the study. Questionnaires were completed either by one of the authors (GAL, $40 \%$ ) or by members of the UKCCSG. Information gathered included congenital abnormalities, clinical features, pretreatment investigations (including chromosome analysis), treatment, and outcome. Follow up continued until October 1988.

Ninety eight children were identified with Down's syndrome and acute leukaemia. Eight patients were excluded from the study: one child was more than 15 years of age at diagnosis and the remainder were incorrectly diagnosed or had insufficient information available. Ninety children were thus included in the study, of whom $63(70 \%)$ had acute lymphoblastic leukaemia, $26(29 \%)$ had acute myeloblastic leukaemia, and one patient had unspecified leukaemia. This distribution is similar to the incidence reported by Rosner and Lee in $1972 .^{7}$ This represents $68 \%$ of the patients on the National Registry with Down's syndrome and acute leukaemia diagnosed and treated in mainland Britain. The 90 children with Down's syndrome in the study were compared with 4377 children without Down's syndrome with acute leukaemia who were ascertained from the National Registry, and treated by UKCCSG members, who were diagnosed between 1971 and 1986 .

Patient characteristics and survival of the two groups were analysed using standard statistical methods. Survival rates were also compared for children with Down's syndrome receiving different intensity treatment. Differences between survival curves were analysed using log rank tests. $^{8}$

Results

CLINICAL FEATURES

The presenting features of the 63 children with 
and 3664 children without Down's syndrome who had acute lymphoblastic leukaemia are shown in table 1. There was no difference between the groups in sex, age, or presenting white cell count. There was a significantly higher proportion of the common immunological phenotype of acute lymphoblastic leukaemia in the group with Down's syndrome $\left(\chi^{2}=4.03\right.$ on $\left.1 \mathrm{df}, \mathrm{p}<0.05\right)$, and a corresponding deficit of $T$ cell acute lymphoblastic leukaemia.

Children with Down's syndrome were classified by mode of treatment. Group $O$ (five patients) received no treatment because either the patient died before treatment started (one patient) or a positive decision was made not to treat (four patients); two of these children had ventricular septal defects with pulmonary hypertension.

Group I (19 patients) received one or two drug induction, and $64 \%$ of the patients available for central nervous system directed treatment received it.

Table 1 Acute lymphoblastic leukaemia: patient characteristics. Results are number (\%)

\begin{tabular}{|c|c|c|}
\hline & $\begin{array}{l}\text { With Down's } \\
\text { syndrome }\end{array}$ & $\begin{array}{l}\text { Without Down's } \\
\text { syndrome }\end{array}$ \\
\hline $\begin{array}{l}\text { Sex: } \\
\text { Male } \\
\text { Female } \\
\text { Total }\end{array}$ & $\begin{array}{l}35(57) \\
26(43) \\
61\end{array}$ & $\begin{array}{l}2095(57) \\
1569(43) \\
3664\end{array}$ \\
\hline $\begin{array}{c}\text { Age (years) } \\
0-1 \\
2 \\
3 \\
4-6 \\
7-9 \\
10-14 \\
\text { Total }\end{array}$ & $\begin{array}{r}6(10) \\
7(11) \\
11(17) \\
16(25) \\
14(22) \\
9(14) \\
63\end{array}$ & $\begin{array}{c}406(11) \\
558(15) \\
584(16) \\
988(27) \\
539(15) \\
589(16) \\
3664\end{array}$ \\
\hline $\begin{array}{l}\text { Presenting } \\
\left(\times 10^{9} / 1\right): \\
<20 \\
20-99 \\
\geqslant 100 \\
\text { Total }\end{array}$ & $\begin{array}{rr}40 & (65) \\
18 & (29) \\
4 & (6) \\
62 & \end{array}$ & $\begin{array}{r}2310(64) \\
859(24) \\
452(12) \\
3621\end{array}$ \\
\hline $\begin{array}{l}\text { Phenotype: } \\
\text { Common } \\
\text { Null cell } \\
\text { T cell } \\
\text { B cell } \\
\text { Total }\end{array}$ & $\begin{array}{rr}31 & (91) \\
2 & (6) \\
1 & (3) \\
0 & \\
34 & \end{array}$ & $\begin{array}{r}1251(75) \\
127(8) \\
264(16) \\
35(2) \\
1677\end{array}$ \\
\hline
\end{tabular}

Table 2 Prognostic factors for patients with Down's syndrome and acute lymphoblastic leukaemia in treatment groups I and II.* Results are number (\%)

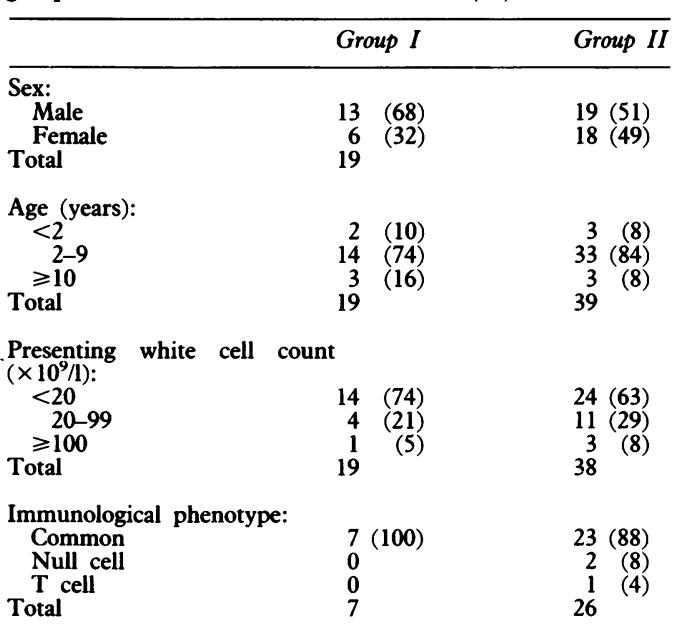

*Group I: minimal treatment; group II: three or more drug induction.
Group II (39 patients) received (more intensive treatment and $34(87 \%)$ received central nervous system directed treatment. Only nine of these patients were not included in United Kingdom acute lymphoblastic leukaemia (UKALL) trials, eight (21\%) were treated on the UKALL $X$ protocol, although many patients did not adhere strictly to the protocol.

Prognostic factors in the treatment groups were compared and there was no significant difference (table 2).

The presenting features of 26 children with Down's syndrome and acute myeloblastic leukaemia were similarly compared with 713 children with acute myeloblastic leukaemia but without Down's syndrome (table 3 ). There is a highly significant difference in age distribution with more children with Down's syndrome under 2 years of age $\left(\chi^{2}=23.97\right.$ on $\left.2 \mathrm{df}\right)$. This difference may in part be accounted for by the high number of erythroleukaemias (M6) observed in the group with Down's syndrome. Erythroleukaemia is predominantly a disease of children under 2 years. Both megakaryocytic leukaemia (M7) and erythroleukaemia (M6) were relatively more common. Erythroleukaemia was significantly more common when compared with all other French-American-British classification (FAB) subtypes $(p=0.004$, Fisher's exact test).

Eight of the patients with acute myeloblastic leukaemia $(31 \%)$ were not treated, seven $(27 \%)$ received only minimal treatment with less than three drugs (group I), 11 patients (42\%) underwent intensive chemotherapy, albeit with treatment adjustments (group II).

Successful chromosome analysis from the leukaemic clones was performed in 12 acute lymphoblastic leukaemia cases and 14 cases of acute myeloblastic leukaemia. The abnormal karyotypes are shown in table 4 . With this limited data no conclusions can be drawn in relation to outcome.

OUTCOME

Acute lymphoblastic leukaemia

The 58 children with acute lymphoblastic

Table 3 Acute myeloblastic leukaemia: patient characteristics. Results are number (\%)

\begin{tabular}{lcc}
\hline & $\begin{array}{c}\text { With Down's } \\
\text { syndrome }\end{array}$ & $\begin{array}{l}\text { Without Down's } \\
\text { syndrome }\end{array}$ \\
\hline $\begin{array}{l}\text { Sex: } \\
\text { Male }\end{array}$ & $15(58)$ & $374(52)$ \\
Female & $11(42)$ & $339(48)$ \\
Total & 26 & 713 \\
Age (years): & & \\
$<2$ & $16(62)$ & $152(21)$ \\
$2-9$ & $8(31)$ & $334(47)$ \\
$>10$ & $26(7)$ & $227(32)$ \\
Total & 26 & 713 \\
Presenting white & cell & \\
count $\left(\times 10^{\prime} / 1\right):$ & $19(73)$ & $378(55)$ \\
$<20$ & $7(27)$ & $198(29)$ \\
$20-99$ & 0 & $110(16)$ \\
श100 & 26 & 686 \\
Total & & \\
FAB subtype*: & $7(44)$ & $475(91)$ \\
M1-5 & $5(31)$ & $29(6)$ \\
M6 & $4(25)$ & $17(3)$ \\
M7 & 16 & 521 \\
Total & & \\
\hline
\end{tabular}

*FAB: French-American-British classification. 
Table 4 Karyotype of abnormal leukaemic clone $(n=8)$

\begin{tabular}{lll}
\hline Type of acute leukaemia & Karyotype & Outcome \\
\hline Acute lymphoblastic & $47 \mathrm{XY},+21, \operatorname{del}(16)(\mathrm{P} 11)$ & Died (infection) \\
Acute lymphoblastic (common) & $47 \mathrm{XX},+21,1 \mathrm{q}^{+}$ & Died (infection) \\
Acute myeloblastic & $47 \mathrm{XX},+21,6 \mathrm{q}^{-}$ & Alive event free \\
Acute myeloblastic & $48 \mathrm{XY}+8,+21$ & Died (no treatment) \\
Acute myeloblastic (M4) & $47 \mathrm{XY},+21,1 \mathrm{p}^{+}, \operatorname{der}(7)$ & Died (infection) \\
Acute myeloblastic (M6) & $47 \mathrm{XX},+21, \mathrm{t}(16+18)(\mathrm{q} 22 ; \mathrm{q} 23)$ & Died (relapse) \\
Acute myeloblastic (M6) & $51 \mathrm{XY},+11,+13,+19,+21,+21$ & Died (relapse) \\
Acute myeloblastic (M7) & $47 \mathrm{XY},+21, \operatorname{del}(7 \mathrm{p} 13-\mathrm{ptder})$ & Died (relapse) \\
\hline
\end{tabular}

leukaemia and Down's syndrome who were treated had a significantly worse overall actuarial survival than those without Down's syndrome who were treated $\left(\chi^{2}=36 \cdot 2\right.$ on $1 \mathrm{df}$, $\mathrm{p}<0.001$ ) (fig 1). The five year survival for those with Down's syndrome was $28 \%$ (95\% confidence interval $14 \cdot 2$ to $42 \cdot 6$ ) compared with $59 \%(95 \%$ confidence interval 56.6 to $60 \cdot 6)$ for those without Down's syndrome.

For the children with acute lymphoblastic leukaemia and Down's syndrome survival rates in the two treatment groups were compared. Relapses and causes of death are summarised in table 5. In the minimally treated group I (19 patients) there were no event free survivors. Only one child has survived and is still receiving chemotherapy after a central nervous system relapse while on treatment. In group II, 11 of the 39 patients $(24 \%)$ are event free survivors with a follow up time of two to nine years from diagnosis and a median event free survival of 18 months (fig 2). There was a significant difference in the relapse free survival between the two groups $(p<0.01)$. In group II six children had central nervous system relapses and two are long term survivors 13 years and eight years from diagnosis, although the latter child is still on continuous treatment four years from relapse. A third child remains on treatment because of recent bone marrow and central nervous system relapse. Two patients had a central nervous system relapse in group I, one patient from group I and one from group II

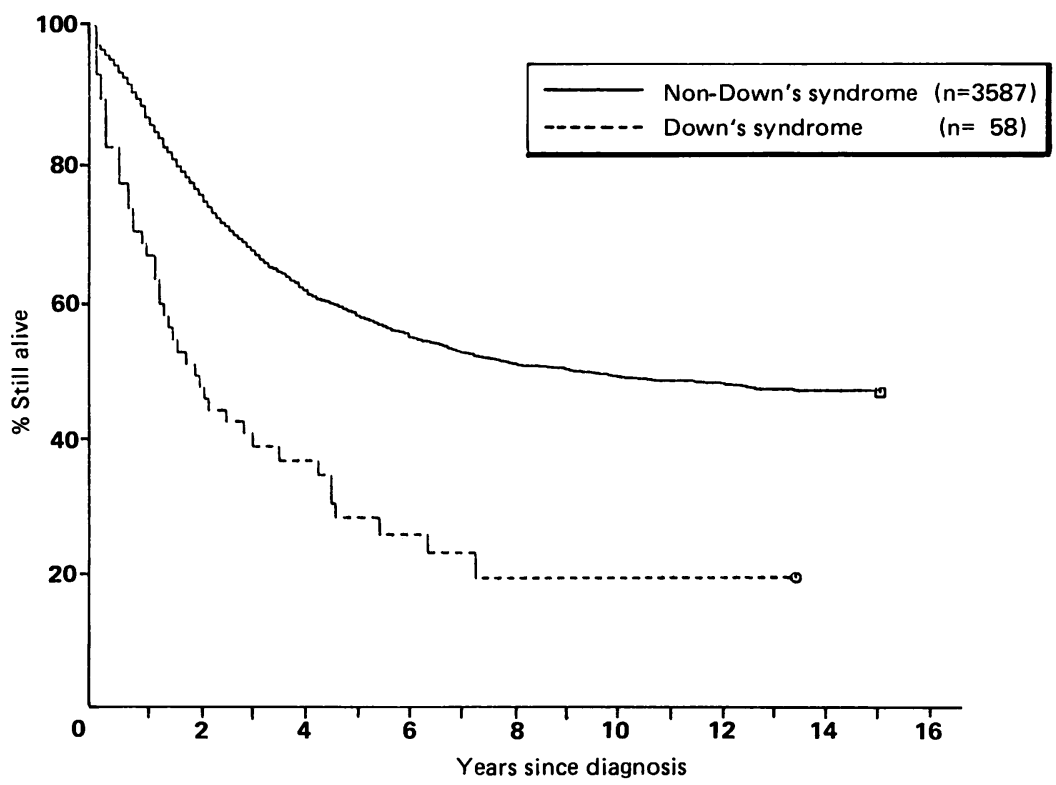

Figure 1 Survival of patients with acute lymphoblastic leukaemia with or without Down's syndrome 1971-86. received no central nervous system directed treatment.

A substantial proportion of patients died from infection: four patients $(21 \%)$ in group I and 11 children $(28 \%)$ from group II. Four of the group II patients died during induction and one during an intensification module. The remaining infections occurred in remission during continuing treatment. In addition one child in group II died of infection but was found to have relapsed at postmortem examination. Deaths occurred at a wide range of ages between 17 months and 14 years. There was a variety of causative organisms. Six patients died due to unidentified pathogens causing septicaemia or pneumonia. In group $I$, two patients died of bacterial septicaemia: one from viral hepatitis and the other from varicella pneumonitis. In group II, most died due to presumed bacterial infections but one patient died from mycoplasma pneumonia, one from Pneumocystis carinii pneumonia, and a further patient died from a combination of measles and $P$ carinii pneumonia (table 6). Two children died as a consequence of their congenital heart disease associated with pneumonia while on continuous treatment.

The analysis of deaths from infection showed no significant difference between the two treatment groups. The five year mortality rate conditional on not having died of their leukaemia was $47 \%$ in group I and $37 \%$ in group II. The deaths in group II tended to occur earlier; the mortality rate during the first year from diagnosis was $28 \%$ in group II compared with only $5 \%$ in group $I$.

\section{Acute myeloblastic leukaemia}

The five year overall survival rate was $19 \%(95 \%$ confidence interval 15.3 to 23.3 ) for those without Down's syndrome and $14 \%$ for those with Down's syndrome and acute myeloblastic leukaemia (the confidence interval could not be calculated because there were insufficient survivors).

Table 5 Outcome with Down's syndrome and acute ymphoblastic leukaemia in treatment groups $I$ and $I I^{*}$

\begin{tabular}{llll}
\hline & Group I & Group II & Total \\
\hline No of children & 19 & 39 & 58 \\
Event free survivors & 0 & 11 & 11 \\
Induction failure & 4 & 1 & 5 \\
Relapse & 9 & 16 & 25 \\
Infective deaths & 4 & $12 \dagger$ & 16 \\
Death associated with & & 2 & 2 \\
$\quad$ congenital heart disease & 0 & 0 & 1
\end{tabular}

${ }^{*}$ Group I: minimal treatment; group II: three or more drug induction.

tOne child died of infection but postmortem examination showed bone marrow relapse. 


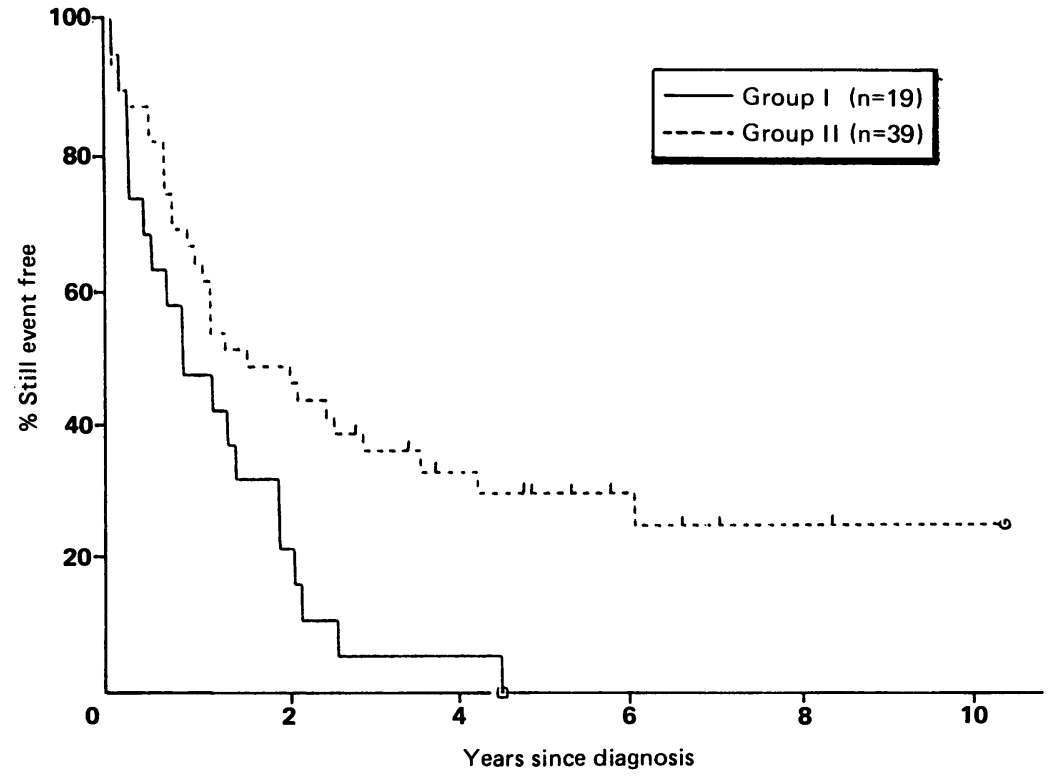

Figure 2 Percentage of patients with Down's syndrome and acute lymphoblastic leukaemia still event free. Vertical bars represent patients with less than 10 years of continuous remission.

Table 6 Causes of death from infection in patients with Down's syndrome

\begin{tabular}{llll}
\hline & Group I & Group II & Total \\
\hline $\begin{array}{l}\text { Total No of infective deaths: } \\
\text { Respiratory infection }\end{array}$ & 4 & 12 & 16 \\
$\quad$ Septicaemia & 1 & 4 & 5 \\
$\begin{array}{l}\text { Organisms isolated: } \\
\text { Varicella }\end{array}$ & 2 & 6 & 8 \\
$\quad$ Hepatitis & 1 & 0 & \\
Measles & 1 & 0 & 1 \\
Mycoplasma & 0 & $1^{*}$ & 1 \\
$\quad$ Candida & 0 & 1 & 1 \\
$\begin{array}{l}\text { Bacteria } \\
\text { Deaths associated with }\end{array}$ & 0 & 2 & 2 \\
$\quad$ congenital heart disease & 0 & $3 \ddagger$ & 5 \\
\hline
\end{tabular}

*Plus Pneumocystis carinii.

fOne patient had candida in addition.

There were no survivors among the seven children in group I; at best, only partial remission was obtained and the last child died of relapse while on treatment. Three children have survived in group II with an event free survival of $27 \%$ with follow up of 33 months to six years. One child was a non-responder with chronic heart failure; two children relapsed on treatment and one off treatment. There were five treatment related deaths. Two children died of infection during induction and one child of fungal pneumonia on continuous treatment. Two children, both off treatment, died due to cardiomyopathy presumably due to daunorubicin; one child had been retreated for a bone marrow relapse. One patient had a known atrial septal defect but the other had a normal echocardiogram at diagnosis.

\section{Discussion}

The children with Down's syndrome in this series have very poor survival rates. Those with acute lymphoblastic leukaemia had a very much lower overall survival rate $(28 \%$ at five years) than those without (59\%). The poor survival occurred despite the prognostic factors, age, and presenting white cell count being similar, and a higher proportion of the children with Down's syndrome and acute lymphoblastic leukaemia had the common acute lymphoblastic leukaemia immunological phenotype. The similarity in the responsiveness of disease is also borne out by the fact that $97 \%$ of children in group II achieved remission, excluding two children who died of infection before remission could be confirmed. This result is very similar to that found in the study of Miller et al using vincristine, prednisolone, and crisantaspase (asparaginase) as induction drugs. ${ }^{9}$

This study does highlight a number of reasons for the survival difference. The treatment regimens used are obviously very important. In the minimal treatment group, only $79 \%$ achieved remission and there were no event free survivors. Tolerance of the continuous treatment was poor in children with Down's syndrome and many reports were received commenting on decreased compliance owing to mucositis, myelosuppression, and infection. There is evidence that within the UKALL trials strict compliance with the protocols substantially reduced the relapse rate. ${ }^{10}$ Peeters and Poon studied 24 patients with Down's syndrome and acute lymphoblastic leukaemia and found intolerance to methotrexate, with patients reaching only $30-50 \%$ of the standard methotrexate dose (methotrexate $20 \mathrm{mg} / \mathrm{m}^{2}$ orally once weekly). ${ }^{11}$ This feature was also noted by Blatt et al, who suggested that there may be abnormal metabolism of methotrexate causing raised serum concentrations. ${ }^{12}$

Primary disease of the central nervous system was not a feature in the children with Down's syndrome but eight children had a central nervous system relapse, two associated with bone marrow relapse. Of the eight children, two had received no treatment directed at the central nervous system. No child developed overt complications from either radiotherapy or intrathecal chemotherapy, although prospective psychological testing was not included in this study. The numbers of children are too small to draw any conclusion as to whether central nervous system directed treatment contributed to the infective deaths. One child died in status epilepticus but had received no central nervous system treatment and another child had epilepsy before diagnosis and received only intrathecal methotrexate. These findings strongly suggest that children with Down's syndrome and acute lymphoblastic leukaemia should receive the same central nervous system directed treatment as those without Down's syndrome.

Robison et al, in their 10 year survey comparing children with acute lymphoblastic leukaemia and without Down's syndrome, found the five year overall survival lower in the group with Down's syndrome ( $50 \%$ compared with $65 \%) .{ }^{13}$ Induction failure was higher in the children with Down's syndrome (19\% compared with $6 \%$ ), but the relapse free survival was not significantly different.

One of the main causes of mortality in children with Down's syndrome but without leukaemia is infection, so the fact that many 
of these children with acute lymphoblastic leukaemia succumb to overwhelming infection is not surprising, although it is a worrying feature in their treatment. Induction deaths owing to infection occurred in $5 \%$ of group I and $13 \%$ in group II. The high incidence continued during maintenance with a further eight children dying in group II. These figures contrast with the incidence of $0.5 \%$ in an analysis of 184 children at the Hospital for Sick Children, London, undergoing induction treatment for acute lymphoblastic leukaemia. ${ }^{14} \mathrm{~A}$ further study from the same centre in 1981 showed $8 \%$ of children died from infection while on continuous treatment. ${ }^{15}$ Most deaths occurred in children under 5 years and as many as $16 \%$ were thought to be due to measles. In the group with Down's syndrome, $24 \%$ died of infection, but no particular pathogen was responsible. Advancing age did not appear to be a protection against infection in these children, who had a mean age of death of 6 years, with $63 \%$ over 5 years of age at the time of death. Five children died of pneumonia, a common problem in children with Down's syndrome, and in two of these congenital heart disease contributed to cause of death. The immune system has been extensively studied in patients with Down's syndrome with conflicting results, but abnormalities of the thymus, ${ }^{16} \mathrm{~T}$ cell and subsets activity, ${ }^{16-19}$ and neutrophil function ${ }^{16}$ have been well documented. Impaired immune surveillance may in part account for the increased incidence of haematological malignancies seen with these children.

The children with Down's syndrome and acute myeloid leukaemia presented at a younger age than controls; this has been reported before $^{13}$ and there was a higher percentage of megakaryocytic leukaemia ${ }^{17}$ and erythroleukaemia. As reported in the paper of Robison et al there was no significant difference in survival from children without Down's syndrome. ${ }^{13}$ The use of doxorubicin or other cardiotoxic drugs must be monitored with care even in children without congenital heart disease-as shown by our two patients who suffered irreversible cardiomyopathy, one of whom had a normal echocardiogram.

We conclude that patients with Down's syndrome and acute leukaemia have a poor prognosis, probably not because their disease is more aggressive, but because of associated congenital abnormalities, poor tolerance of infection, and possible altered drug metabolism that makes appropriate treatment difficult. Modification of cytotoxic treatment to prevent treatment related deaths, however, is likely to lead to poor response to treatment so that the only effective approach to treatment is to give standard protocols with full supportive care and an aggressive policy for detection and treatment of infections.

Gill Levitt and Judith Chessells are supported by the Leukaemia Research Fund. The Childhood Cancer Research Group is supported by the Department of Health and the Scottish Hom and Health Department. The United Kingdom Children's Cancer Study Group is supported by the Cancer Research Campaign. We thank the members of the UKCCSG for providing patient information and Jeanette Stevens for typing the manuscript.

We are grateful for the Office of Population Censuses and Surveys, the Information Services Division of the Common Sevices Agency of the Scottish Health Service, the Registra General for Scotland, and regional cancer registries for providin copies of notifications of childhood leukaemia cases. We thank copies of notifications of childhood leukaemia cases. We than the National Health Service Central Registers at Southport and Edinburgh for notification of deaths and the flagging of surviTers. We are grateful to Dr M Potok for helping with computing The following members of the UKCCSG kindly provided patient information: Dr C Bailey, Dr P Barbor, Dr F Breath nach, Professor J Chessells, Dr S Dempsey, Dr T Eden, D I Hann, Dr F Hill, Dr J Kernahan, Dr J Kingston, Dr I Lewis, Jones, Dr A Oakhill, Dr R Shannon, and Dr E Thompson.

1 Brewster HF, Cannon HE. Acute lymphatic leukemia: report of a case in an eleventh month mongolion idiot. New report of a case in an eleventh month mongolion idiot. New
Orleans Medical and Surgical foumal 1930;82:872-3.

2 Krivit W, Good RA. Simultaneous occurrence of mongolism and leukaemia. Am 7 Dis Child 1957;94:289-93.

3 Miller RW. Down's syndrome, other congenital malformaions and cancer among the sibs of leukemic children. $N$ Engl f Med 1963;268:393.

4 Barbet R, Spiers P. Oxford survey of childhood cancer: progress report II. Monthly Bulletin Ministry of Health 1964;23:46-52.

5 Baird PA, Sadovnick AD. Life expectancy in Down syndrome. F Pediatr 1987;110:849-54.

6 Draper GJ, Stiller CA, Fearnley H, et al. United KingdomEngland and Wales, national registry of childhood
tumours, 1971-1980. In: Parkin DM, ed. International incidence of childhood cancer. IARC Scientific Publications, No 87. Lyon: IARC, 1988:295-8.

7 Rosner F, Lee SL. Down's syndrome and acute leukemia: meloblastic or lymphoblastic? Am $\mathcal{f}$ Med 1972;53:203-18.
myel

8 Peto R, Pike MC, Armitage P, et al. Design and analysis of randomised trials requiring prolonged observation of each patient. II: Analysis and examples. Br $\mathcal{F}$ Cancer 1977;35: patien $1-39$.

9 Miller DR, Leikin S, Albo V, et al. Prognostic factors and therapy in acute lymphoblastic leukemia of childhood CCG-141. Cancer 1983;51:1041-9.

10 Eden OB, Stiller CA, Gerrard MP. Improved survival for childhood acute lymphoblastic leukaemia: possible effect of protocol compliance. Paediatric Haematology and Oncology 1988;5:83-91.

11 Peeters $M$, Poon A. Down syndrome and leukaemia: unusual clinical aspects and unexpected methotrexate sensitivity. Eur $\mathcal{f}$ Pediatr 1987; 146:416-22.

12 Blatt J, Albo V, Prin W, et al. Excessive chemotherapyrelated myelotoxicity in children with Down syndrome and acute lymphoblastic leukaemia. Lancet 1986;ii:914.

13 Robison LL, Nesbit ME, Harland N, et al. Down syndrome and acute leukemia in children: a 10-year retrospective and acute leukemia in children: a 10-year retrospective
survey from Childrens Cancer Study Group. $\mathcal{F}$ Pediatr survey from Child

14 Chessells JM, Leiper AD. Infection during remission induction in childhood leukaemia. Arch Dis Child 1980;55: tion in $118-23$.

15 Ninane J, Chessells JM. Serious infections during continuing treatment of acute lymphoblastic leukaemia. Arch Dis Child $1981 ; 56: 841-4$.

16 Levin S. The immune system and susceptibility to infections Down's syndrome. Prog Clin Biol Res 1987;246:143-62. 17 Epstein LB, Philip R. Abnormalities of the immune response
to influenza antigen in Down's syndrome. Prog Clin Biol Res 1987;246:163-82.

18 Lockitch G, Singh VK, Puterman ML, et al. Age-related changes in humoral and cell-mediated immunity in Down syndrome children living at home. Pediatr Res 1987;22:536-40.

19 Montagna D, Maccario R, Ugazio AG, et al. Cell-mediated cytotoxicity in Down syndrome: impairment of allogenic mixed lymphocyte reaction, NK and NK-like activities. mixed lymphocyte reaction,

20 Lewis DS. Association between megakaryoblastic leukaemia and Down syndrome. Lancet 1981;ii:695. 